\title{
Mortality risk factors for calves entering a multi-location white veal farm in Ontario, Canada
}

\author{
Charlotte B. Winder, David F. Kelton, and Todd F. Duffield ${ }^{1}$ \\ Department of Population Medicine, University of Guelph, Ontario, Canada, N1G 2W1
}

\begin{abstract}
Mortality in preweaned dairy-breed calves, whether they are replacement dairy heifers, veal animals, or dairy beef animals, represents both a welfare issue and a source of economic loss for the industries involved. Studies describing morbidity and mortality in veal calves have illustrated different management practices and requirements in terms of housing and nutrition around the world. Studies examining the rearing of replacement dairy heifers have shown that rates of morbidity and mortality can vary dramatically between farms, perhaps reflecting differences in management strategies. It has been over 2 decades since morbidity and mortality in veal calves in Ontario were described. The objective of this retrospective population cohort study was to describe mortality and determine whether on-arrival information could be used to predict mortality risk. Predictors could be used to both better classify and group calves on arrival and provide feedback to suppliers about the characteristics of the highest- and lowest-risk calves. We collected data from 10,910 calves entering 7 barns of a single white veal farm, all in Ontario, from January 1 to December 31, 2014. Calves were followed until death or marketing (typically 140 to $150 \mathrm{~d}$ ). We developed logistic regression models to determine the effects of weight on arrival, season of arrival, supplier, sex, barn, and purchase price on the risk of total mortality, early mortality (0-21 d after arrival), and late mortality ( $>21 \mathrm{~d}$ after arrival). We identified significant associations between season, barn, supplier, weight, and total mortality risk, with lighter-weight calves arriving in winter being at increased risk. Early mortality was significantly associated with weight, season, barn, and supplier, and tended to be associated with standardized price; lighter-weight calves arriving in winter at lower prices were at increased risk. Late mortality was significantly associated with season of arrival, barn, and supplier. On-arrival measures better
\end{abstract}

Received April 21, 2016.

Accepted August 8, 2016.

${ }^{1}$ Corresponding author: tduffiel@uoguelph.ca predicted early mortality compared with late or total mortality. A further exploration of risk factors from the dairy farm of origin for veal calf mortality would serve to improve the productivity and welfare of calves of both sexes born on dairy farms.

Key words: calf, mortality, veal

\section{INTRODUCTION}

Although dairy cows may be bred to beef sires or to sexed dairy sire semen, the use of conventional dairybreed semen accounts for the vast majority of pregnancies (De Vries et al., 2008). Therefore, we expect about half of the calvings on the approximately 959,600 cows on Canadian dairy farms (Canadian Dairy Commission, 2016) to produce a male dairy calf. Less than $7 \%$ of Canadian dairy producers report routinely euthanizing male calves at birth, and over $80 \%$ report selling all male calves within 2 wk of birth (D. F. Kelton, unpublished data). In 2015, over 200,000 veal calves were slaughtered in Ontario and Quebec (Agriculture and Agri-Food Canada, 2015); these provinces constitute approximately two-thirds of the Canadian dairy cattle population (Canadian Dairy Commission, 2016). The majority of Canadian veal is marketed nationally, but Canada also exports approximately 2,000 t of veal each year, virtually all of it to the United States (Agriculture and Agri-Food Canada, 2015).

Mortality in preweaned dairy-breed calves, whether they are replacement dairy heifers, veal animals, or dairy beef animals, represents both a welfare issue and a source of economic loss for the industries involved. Morbidity and mortality in veal calves have been described in multiple production systems (Wilson et al., 2000; Moore et al., 2002; Pardon et al., 2012), but conditions can vary greatly in terms of management practices and requirements in different regions and countries. Varying management strategies may in part account for the wide range of morbidity and mortality rates described in dairy heifers (Trotz-Williams et al., 2008; Raboisson et al., 2013). The last report describing morbidity and mortality in Ontario veal production was published over 2 decades ago (Sargeant et al., 
1994a,b); since then, substantial changes have occurred in the dairy industry (LeBlanc et al., 2006).

One-third of mortality in heifer calves $<21 \mathrm{~d}$ of age in the United States is attributable to risk factors present on the day of birth, including colostrum management and difficulties associated with calving (Wells et al., 1996). Bull calves are at higher risk for dystocia (Lombard et al., 2007), primarily due to their increased birth weight compared with heifer calves (Johanson and Berger, 2003). Calves born to multiparous or primiparous cows or heifers that experience dystocia have a significantly increased mortality risk (Wells et al., 1996; Lombard et al., 2007), and the risk may be compounded by a lower vigor score at birth. Newborn calves with poor vigor are significantly less likely to suck, and willingly ingest less colostrum than calves born with a higher vigor score (Vasseur et al., 2009). Colostrum feeding is variable among farms (Kehoe et al., 2007), and the ability of calves to willingly suck colostrum soon after birth may be more crucial to their risk of failure of passive transfer (FPT) on some farms than on others.

Failure of passive transfer may be farm-specific (Moore et al., 2002; Trotz-Williams et al., 2008; Windeyer et al., 2014) and can be as high as 60\% (Tyler et al., 1998). Although it has been reported that rates are similar in bull and heifer calves (Trotz-Williams et al., 2008), FPT is still a potentially large source of morbidity and mortality risk among veal calves. The main effect of FPT is reflected in morbidity and mortality during the first $3 \mathrm{wk}$, but some work has shown an effect on calf health up to 10 wk of age (Tyler et al., 1998).

Early nutrition quality and quantity can also affect mortality risk (Godden et al., 2005), and the nutritional planes of veal calves on the dairy farm of origin may differ greatly between farms. Low nutritional planes in the first week of life during even temperate Canadian winters can cause significant weight loss (Borderas et al., 2009), and in calves born to dystocia, may exacerbate the effects of a difficult calving on generation of body heat (Murray and Leslie, 2013; Roland et al., 2016). Nutritional stress during the first week also results in higher cortisol levels (Roland et al., 2016), which may affect calves' ability to withstand infectious challenges during transport and mixing at a veal or heifer rearing facility. A study of on-arrival risk factors for veal calves arriving at 5 facilities in the northeastern United States described $21.4 \%$ of calves as either emaciated or having no discernable subcutaneous fat on arrival (Wilson et al., 2000).

Based on the lack of recent information regarding the health and performance of male dairy calves in the meat sector in Canada, the objective of our study was to describe veal calf mortality and determine whether recorded on-arrival information from a large white veal farm could be used to predict mortality risk. If associations between on-arrival data and mortality existed, we expected that this information could be used to better classify and group calves on arrival, and to provide feedback to suppliers on the characteristics of calves at the highest and lowest risk.

\section{MATERIALS AND METHODS}

This study was conducted in cooperation with a white veal producer that had 7 barns in different geographic locations in the province of Ontario, Canada. Data were collected retrospectively from all calves that entered all facilities as part of routine monitoring by facility staff members. Calves were raised for approximately 140 to $150 \mathrm{~d}$ before slaughter. Occasionally, calves that performed more poorly were held back and slaughtered at a slightly older age; as a result, 2 mortality events in our data set occurred after $150 \mathrm{~d}$.

\section{Data Collection}

Records for 10,910 calves entering 7 different barns from January 1 to December 31, 2014, were collected and offered for analysis. Calves were identified by Canadian Cattle Identification Agency (CCIA) tag number and followed until finishing. Farm entry date, supplier, sex, weight on arrival, location in the barn, and purchase price were recorded. A separate record of mortality events included CCIA tag number, entry date, supplier, date of death, and on-farm diagnosis by staff. Mortality record collection extended into 2015 to capture all possible mortalities for calves entering the system late in 2014. Barns used different management strategies: barns 1, 4, and 5 housed calves in individual pens, although barn 5 housed a small subset of calves in very small groups (3 calves) from 9 wk of age onward. In barn 2, all calves were housed in individual pens in early life, and later in small groups of 8 calves per pen. Calves in barns 1, 2, 4, and 5 were fed milk manually. Barns 3, 6, and 7 housed calves in large groups of approximately 60 calves per pen, and calves were fed with automated feeders. Employees and management strategies differed among barns, but the farm manager stated that their policy in 2014 was that no calves in any barns were sold early as culls; therefore, all calves would have died, been euthanized, or completed the finishing process to slaughter. Barns 1, 2, and 3 were located on the same property and had a single receiving facility. Calves were sorted on arrival based on entry 
weight and general appearance: lighter calves or those with poorer appearance (e.g., poorer body condition, evidence of diarrhea) were sorted to barn 1 , and the heaviest and best-looking calves were sorted to barn 3. Staff judged calves' appearance subjectively in the receiving barn for barns 1, 2, and 3; no standardized health scoring system was used. Barns 4, 5, 6, and 7 were all located on separate properties.

Data were checked for completeness of records, and entries containing missing data were removed. Receiving dates were categorized by month and season (winter: December, January, and February; spring: March, April, and May; summer: June, July, and August; fall: September, October, and November).

Mortality was classified as "early" if it occurred on or before $21 \mathrm{~d}$ following entry into the system; it classified as "late" if it occurred after $21 \mathrm{~d}$. Calf entry date was based on the first recorded CCIA tag scan, which occurred when calves were placed in each barn; this may have been delayed by one or more days after arrival if calves were held in the separate receiving barn or if initial scanning was delayed. Three mortality events occurred on $1 \mathrm{~d}$ before entry scanning; these calves were kept in the data set, and this was thought to highlight the possibility of 1- to 2-d lags in entry scanning. We chose the first $21 \mathrm{~d}$ in the veal production system as a cut-point to help identify risk factors present on arrival that may be associated with early mortality, as it is common for mortality to be the highest during the first 3 to 4 wk after birth or arrival at a calf facility (Moore et al., 2002; Pardon et al., 2012; Raboisson et al., 2013).

Barn staff also recorded the presumed cause of death or reason for euthanasia. Conditions listed were accident, anaphylaxis, arthritis, diarrhea, emaciation, navel/peritonitis, neurological issues, pneumonia, mycoplasma pneumonia, rumen bloat, sudden death, ulcers, and unknown. The majority of the diagnoses were determined by farm staff based subjectively on ante-mortem clinical signs; no standardized diagnostic protocol was used.

We identified 342 suppliers of calves; these represented individual dairy farms and commercial calf purchasers that supplied from 1 calf to over a thousand calves in 2014. Nine suppliers shipped more than 200 calves during the year of the study, and they were assigned a unique designation for further investigation. A tenth category ("other") encompassed all remaining suppliers. The 9 identified suppliers accounted for $34 \%$ of all calves, and individually provided between 3 and $10 \%$ of all calves.

We divided the price paid per calf on arrival by weight to create a price per pound of calf entering the production system. Although this price depended on calf quality, market fluctuations also accounted for much of the variability in calf price per pound throughout the year. We created a new variable, standardized price, to account for some of this variability and reflect more of the buyer's opinion of calf quality rather than market fluctuations. We determined standardized price by calculating an average monthly price per pound and then subtracting that value from the price paid per pound for each calf. This variable was the only price variable retained for further analysis.

\section{Statistical Analysis}

Receiving data, including CCIA tag number, date of entry to the barn, supplier, sex, weight at arrival, barn, and purchase price, were imported from Excel (Microsoft Corp., Redmond, WA) into STATA13 (StataCorp, College Station, TX) and checked for completeness. Mortality records (CCIA tag number, entry date, supplier, date of death, and on-farm diagnosis) were merged and cross-matched using CCIA tag number, entry date, and supplier. Of 832 total deaths, 8 could not be matched using these variables and were discarded from the analysis.

We reviewed the descriptive statistics and discarded sex from further analysis because female calves represented $<1 \%$ of all calves received. We graphed days from arrival to death as a Kaplan-Meier failure function to further describe when mortality occurred. We built 3 explanatory models for the separate outcomes of total mortality, early mortality $(<21 \mathrm{~d})$, and late mortality $(>21 \mathrm{~d})$. We performed univariable logistic regression for the explanatory variables of supplier, entry season, weight on arrival, and standardized price. Variables significant at a liberal $P<0.20$ were considered to include in the multivariable models. All variables considered for the multivariable models were checked for collinearity using the Spearman rank coefficient; a variable was considered collinear if the correlation coefficient was $>0.70$. We assessed continuous variables for linearity. Weight appeared to be linear for the majority of the data, although anomalies occurred at light and very heavy entry weights. These weights reflected few data points, and weight was considered a linear variable for our analysis. We built multivariable models by manual step-wise forward selection. Variables were retained in the multivariable model if they were significant at $P$ $<0.05$. We assessed rejected variables for confounding, and kept them in the model only if their removal changed the coefficients of the remaining variables by $>20 \%$. First-order interaction terms for all variables in the final model were evaluated and retained if significant. Models were assessed for fit using the Hosmer- 


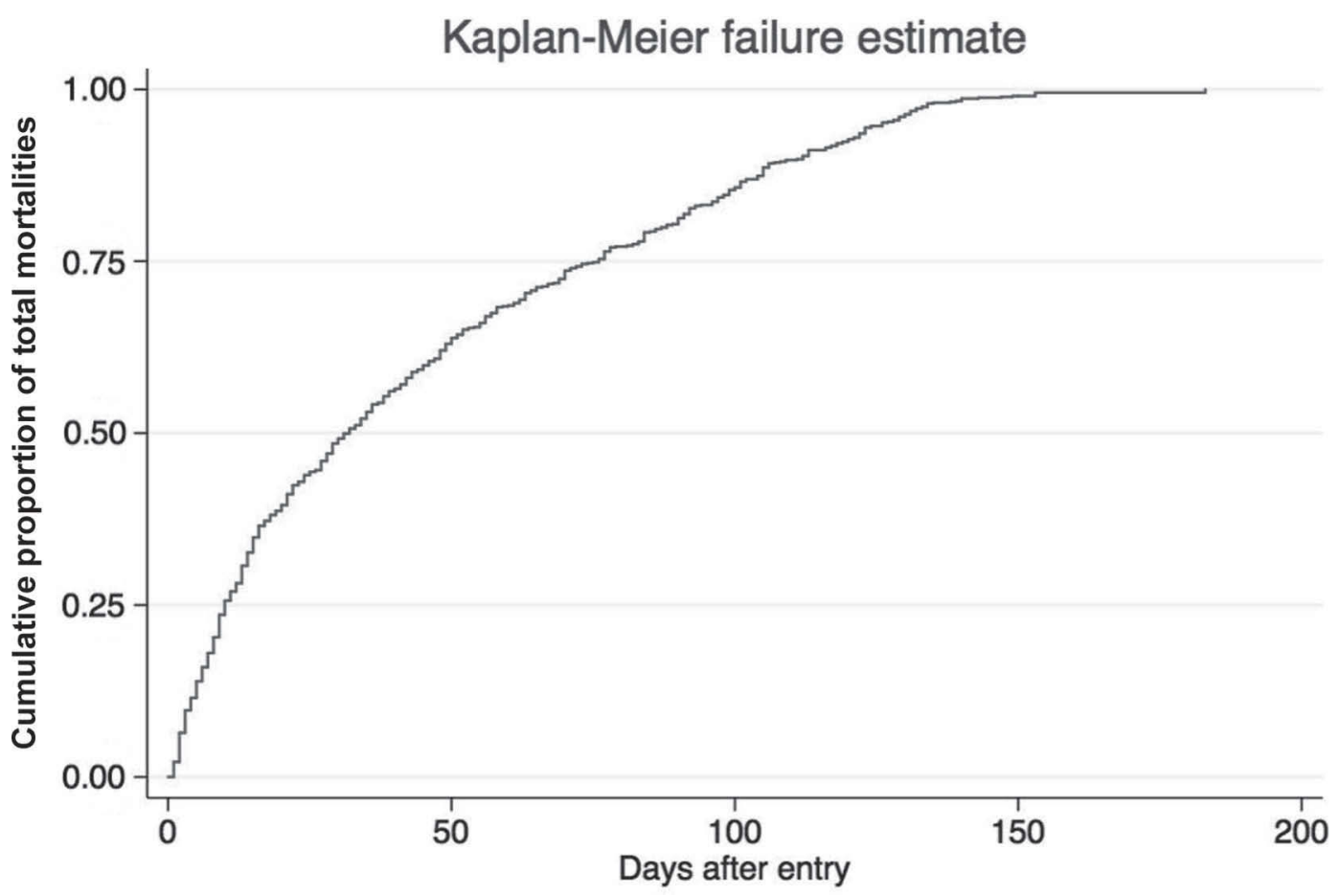

Figure 1. Kaplan-Meier failure estimate: days after entry at which death occurred for the 824 total mortalities (of 10,910 calves entering all locations of the veal facility during calendar year 2014).

Lemeshow goodness-of-fit test. We assessed the predictive ability of each model by examining the area under a receiver operator characteristic (ROC) curve. We also evaluated a Cox-proportional hazard model for total mortality to determine if the predictor variables in that model differed from those identified as important in the logistic regression model.

\section{RESULTS}

\section{Descriptive Statistics}

Entry Information. Of the 10, 910 records, 24\% entered the barns in winter, $28 \%$ in spring, $25 \%$ in summer, and $23 \%$ in fall. The proportion of total arrivals by month ranged from $7 \%$ to $12 \%$. Capacity was not equal across the 7 barns, and finishing ranged from $5 \%$ to $26 \%$ of all calves.

Entry weight ranged from 64 to $222 \mathrm{lb}(29-101 \mathrm{~kg})$, with a mean of $106 \mathrm{lb}(48 \mathrm{~kg}$; SD $11 \mathrm{lb}, 5 \mathrm{~kg}$ ); $93 \%$ of calves were between 90 and $125 \mathrm{lb}(41$ and $57 \mathrm{~kg}$ ) at entry.

The purchase price per calf ranged from Can $\$ 7$ to $\$ 560$ per calf, with a mean of Can $\$ 235$ (SD Can $\$ 73$ ). For $56 \%$ of calves, the price was between Can $\$ 200$ and $\$ 300$; for $96 \%$ of calves, the price was between Can $\$ 100$ and $\$ 400$. Price was then standardized by weight, and mean price per pound was Can $\$ 2.24$ (range Can $\$ 0.01$ to $\$ 5.69$, SD Can $\$ 0.65)$. The standardized price per pound ranged from - Can $\$ 2.14$ to $\$ 3.05$, with a mean of Can\$0.02 (SD Can\$0.45).

Total Mortality. The total mortality for 2014 was $7.6 \%$. By season, mortality was $7 \%$ in fall, $7 \%$ in summer, $8 \%$ in spring, and $8.3 \%$ in winter. Mortality by month ranged from 5\% (December) to 14\% (March). Three months had mortality over 9\% (January, February, and March). Mortality by barn ranged from 4 to $13 \%$. Mortality for the 9 identified suppliers ranged from 2 to $11 \%$, and mortality from the remaining suppliers (representing $66 \%$ of all calves) was $9 \%$. Of all mortalities, the most common on-farm diagnoses were emaciation $(21 \%)$, respiratory disease $(16 \%)$, gastrointestinal causes $(14 \%)$, and sudden death (13\%). Days from entry to death are presented in Figure 1.

Early Mortality. Early mortality was 3\% and represented $42 \%$ of all deaths on the farm. By season, early mortality was $2 \%$ in fall, $2 \%$ in summer, $3 \%$ in spring, and $6 \%$ in winter. Early mortality represented $60 \%$ of mortalities in winter, $43 \%$ in spring, $31 \%$ in summer, and $29 \%$ in fall. Early mortality by month ranged from $25 \%$ (April) to 66\% (February). The proportion of total mortality attributed to early mortality by season was $33 \%$ in summer, $35 \%$ in fall, $39 \%$ in spring, and $42 \%$ in winter. The proportion of early mortality by barn 
ranged from 28 to $58 \%$. Early mortality as a proportion of total mortality by supplier ranged from 10 to $58 \%$ for the 9 identified suppliers and was $38 \%$ of total mortality among the remaining suppliers.

\section{Predictors of Mortality}

Predictors of Total Mortality. The final model for total mortality is presented in Table 1. Calves who were lighter on arrival had increased mortality risk, and this effect was significant but slight; a calf 10 pounds $(4.5 \mathrm{~kg})$ lighter on arrival had 1.1 times greater odds of dying. Season of arrival was also a significant predictor of mortality; calves arriving in winter [odds ratio $(\mathbf{O R})$ $=1.9, P<0.001]$ and spring $(\mathrm{OR}=1.8, P<0.001)$ were more likely to die than calves arriving in the fall. Barn was also associated with mortality. We used barn 1 as the referent group; it housed the second greatest number of calves and had the closest mortality to the mean. Barns $2(\mathrm{OR}=1.6, P<0.001), 3(\mathrm{OR}=2.4, P$ $<0.001)$, and $6(\mathrm{OR}=1.6, P=0.01)$ had significantly higher odds of mortality, and entry to barn 5 had a protective effect $(\mathrm{OR}=0.4, P<0.001)$. The 9 identified suppliers were examined against the "other" category, which accounted for the remainder. One of the 9 suppliers had an increased mortality risk (supplier $\mathrm{H}$, OR $=3.2, P<0.001)$ and 2 were protective (supplier $\mathrm{D}$,

Table 1. Final multivariable model of predictors of total mortality in 2014 for 10,910 calves entering a white veal farm with multiple geographic locations

\begin{tabular}{lccc}
\hline Item & Odds ratio & $P$-value & $95 \%$ CI \\
\hline $\begin{array}{l}\text { Weight (per pound) } \\
\text { Season of arrival }\end{array}$ & 0.99 & 0.03 & $0.98-1.00$ \\
Spring & & & \\
Summer & 1.83 & $<0.001$ & $1.46-2.30$ \\
Winter & 1.25 & 0.07 & $0.98-1.58$ \\
Barn $^{2}$ & 1.88 & $<0.001$ & $1.50-2.36$ \\
2 & & & \\
3 & 1.59 & $<0.001$ & $1.24-2.23$ \\
4 & 2.39 & $<0.001$ & $1.88-3.05$ \\
5 & 1.16 & 0.35 & $0.85-1.60$ \\
6 & 0.40 & $<0.001$ & $0.26-0.63$ \\
7 & 1.63 & 0.01 & $1.12-2.36$ \\
Supplier & 1.30 & 0.16 & $0.90-1.88$ \\
A & & & \\
B & 1.20 & 0.39 & $0.79-1.83$ \\
C & 1.86 & 0.06 & $0.98-3.53$ \\
D & 0.86 & 0.37 & $0.61-1.20$ \\
E & 0.57 & $<0.001$ & $0.43-0.76$ \\
F & 0.94 & 0.88 & $0.41-2.13$ \\
G & 0.43 & $<0.01$ & $0.27-0.69$ \\
H & 1.07 & 0.67 & $0.78-1.50$ \\
& 3.20 & $<0.001$ & $1.88-5.46$ \\
\hline
\end{tabular}

${ }^{1}$ Fall was the referent category.

${ }^{2}$ Barn 1 was the referent category.

"Other" was the referent category (accounting for $66 \%$ of all calves received).
$\mathrm{OR}=0.57, P<0.001 ;$ and supplier $\mathrm{F}, \mathrm{OR}=0.43, P$ $<0.1)$.

The total mortality logistic regression model appeared to fit the data well, as indicated by a nonsignificant Hosmer-Lemeshow goodness-of-fit test. However, the predictive ability of the model was poor (area under ROC curve $=0.65$ ). We built a Cox-proportional hazard model through manual forward selection, and predictors in the final model were the same as those in the final logistic regression model.

Predictors of Early Mortality. Weight on arrival was a significant predictor of early mortality; calves that entered 10 pounds $(4.5 \mathrm{~kg}$ ) lighter had 1.4 times the odds of mortality in the first $21 \mathrm{~d}$. Season was highly significant: calves that arrived in winter $(\mathrm{OR}=$ $3.2, P<0.001)$ and spring $(\mathrm{OR}=2.2, P<0.001)$ had greater odds of mortality than calves that entered in fall. We used barn 1 as the referent group, and all other barns were significantly different; barns $2,3,4,6$, and 7 had higher early mortality risk and barn 5 had lower early mortality risk. Standardized price (per dollar per pound) tended to be predictive of early mortality risk $(\mathrm{OR}=0.7, P=0.06)$. Two suppliers had increased risk of early mortality compared with the "other" category (supplier $\mathrm{B}, \mathrm{OR}=2.6, P=0.04$; and supplier $\mathrm{H}$, OR $=3.4, P<0.01$ ) and 1 was protective (supplier $\mathrm{F}, \mathrm{OR}$ $=0.4, P=0.05)$. Results are summarized in Table 2 .

A nonsignificant Hosmer-Lemeshow goodness-of-fit test indicated that the model fit the data well, and the predictive ability of the model was considered fair (area under the ROC curve $=0.72$ ).

Predictors of Late Mortality. Calves that arrived in spring had increased risk of late mortality compared with calves that arrived in fall $(\mathrm{OR}=1.6, P<0.01)$. Compared with calves in barn 1, those in barns 2 (OR $=1.7, P<0.01)$ and $3(\mathrm{OR}=1.8, P<0.001)$ had a significantly higher late mortality risk, and barn 5 $(\mathrm{OR}=0.4 ; P<0.01)$ had a sparing effect. Two suppliers had a higher late mortality risk than the "other" category (supplier A, OR $=1.7, P=0.02$; and supplier $\mathrm{H}, \mathrm{OR}=2.8, P=0.01$ ), and 2 were protective (supplier $\mathrm{D}, \mathrm{OR}=0.6, P<0.01$; and supplier $\mathrm{F}, \mathrm{OR}=0.5, P=$ 0.02). Results are summarized in Table 3.

A nonsignificant Hosmer-Lemeshow goodness-of-fit test indicated that the model fit the data well, and the predictive ability of the model was considered poor (area under the ROC curve $=0.64$ ).

\section{DISCUSSION}

The determination of which on-arrival risk factors, if any, are associated with increased mortality rates during the veal production cycle may be valuable for 
the early identification, isolation, and treatment of high-risk calves, as well as for feedback to suppliers to appropriately compensate the farm of origin based on the quality of calves they sell.

Total mortality was higher in the winter and spring of 2014. The effect of season was greatest for early mortality: calves arriving in winter had over 3 times the risk of dying in the first $21 \mathrm{~d}$ compared with calves arriving in fall. Seasonal variation in mortality is likely to be multifactorial and could reflect changes in colostrum management, nutrition, ventilation, or infection pressure. As well, the effects of dystocia on calf vitality could be compounded in cold months, as the heat-generating mechanisms of the calf may be impaired (Murray and Leslie, 2013; Roland et al., 2016).

The effect of barn and management was a significant predictor of both early and late mortality, and we observed the same pattern in each model. This finding was not unexpected based on the variability in reported mortality rates between farms in the published literature. Surprisingly, although perceived higher-risk calves (according to the producer) were preferentially sorted to barn 1 and lower-risk calves to barn 3, we observed the opposite risk of death for both early and late mortality. Criteria for "high-risk" calves were not specified by the

Table 2. Final multivariable model of predictors of early mortality ( $<21 \mathrm{~d}$ of entry) in 2014 for 10,910 calves entering a white veal farm with multiple geographic locations

\begin{tabular}{lccc}
\hline Item & Odds ratio & $P$-value & $95 \%$ CI \\
\hline Weight (per pound) & 0.97 & $<0.001$ & $0.96-0.98$ \\
Standardized price $^{1}$ & 0.73 & 0.06 & $0.53-1.01$ \\
Season of arrival $^{2}$ & & & \\
Spring & 2.18 & $<0.001$ & $1.51-3.15$ \\
Summer & 1.25 & 0.27 & $0.84-1.85$ \\
Winter & 3.21 & $<0.001$ & $2.26-4.57$ \\
Barn $^{3}$ & & & \\
2 & 1.55 & 0.05 & $1.01-2.37$ \\
3 & 3.69 & $<0.001$ & $2.47-5.51$ \\
4 & 2.32 & $<0.001$ & $1.46-3.70$ \\
5 & 0.44 & 0.03 & $0.21-0.90$ \\
6 & 3.03 & $<0.001$ & $1.70-5.40$ \\
7 & 2.37 & $<0.01$ & $1.39-5.40$ \\
Supplier & & & \\
A & 0.32 & 0.05 & $0.10-1.01$ \\
B & 2.59 & 0.04 & $1.05-6.37$ \\
C & 0.83 & 0.47 & $0.51-1.37$ \\
D & 0.74 & 0.21 & $0.45-1.19$ \\
E & 1.17 & 0.84 & $0.25-5.55$ \\
F & 0.39 & 0.05 & $0.16-0.98$ \\
G & 1.26 & 0.30 & $0.82-1.93$ \\
H & 3.40 & $<0.01$ & $1.60-7.22$ \\
\hline
\end{tabular}

${ }^{1}$ Standardized price $=$ (average monthly price per pound for all calves received) - (price per pound for the individual calf).

${ }^{2}$ Fall was the referent category.

${ }^{3}$ Barn 1 was the referent category.

" "Other" was the referent category (accounting for $66 \%$ of all calves received)
Table 3. Final multivariable model of predictors of late mortality ( $>21$ d of entry) in 2014 for 10,910 calves entering a white veal farm with multiple geographic locations

\begin{tabular}{lccc}
\hline Item & Odds ratio & $P$-value & $95 \%$ CI \\
\hline $\begin{array}{l}\text { Season of arrival } \\
\text { Spring }\end{array}$ & 1.62 & $<0.01$ & $1.22-2.13$ \\
Summer & 1.24 & 0.14 & $0.93-1.65$ \\
Winter & 1.24 & 0.16 & $0.92-1.66$ \\
Barn $^{2}$ & & & \\
2 & 1.65 & $<0.01$ & $1.24-2.20$ \\
3 & 1.82 & $<0.001$ & $1.35-2.45$ \\
4 & 0.65 & 0.07 & $0.41-1.04$ \\
5 & 0.37 & $<0.01$ & $0.21-0.65$ \\
6 & 1.19 & 0.48 & $0.74-1.90$ \\
7 & 0.80 & 0.39 & $0.47-1.35$ \\
Supplier & & & \\
A & 1.72 & 0.02 & $1.10-2.69$ \\
B & 1.40 & 0.46 & $0.57-3.41$ \\
C & 0.82 & 0.38 & $0.52-1.28$ \\
D & 0.60 & $<0.01$ & $0.42-0.86$ \\
E & 1.02 & 0.98 & $0.39-2.66$ \\
F & 0.53 & 0.02 & $0.30-0.91$ \\
G & 0.89 & 0.60 & $0.58-1.37$ \\
H & 2.77 & 0.01 & $1.35-5.71$ \\
\hline
\end{tabular}

${ }^{1}$ Fall was the referent category.

${ }^{2}$ Barn 1 was the referent category.

"Other" was the referent category (accounting for $66 \%$ of all calves received).

producer, so it is not possible to comment on how appropriate the definition might have been. However, we do know that a component of the "high-risk" designation was entry weight, and increased weight was protective of mortality in the first $21 \mathrm{~d}$. Despite the inclusion of weight as a variable in the early mortality model, the effect of barn was still significant. Other management factors, which might include housing type, may have been responsible for the inverse relationship between barn and mortality based on what was expected. Barn 3 housed calves in large groups on an automated feeder, but so did barn 5 , which reported the lowest early and total mortality rates. A closer examination of employee care and management strategies in each barn may help explain the variations in mortality risk among barns.

A greater weight on arrival was protective for early mortality. Weight is a function of size at birth, age, and nutrition, and because we did not have these variables in our data set, we cannot tease apart the contributions of these factors. If calves arrived at a similar age and frame size, weight could be an acceptable proxy for body condition. However, it is not currently possible or practical to assess age on arrival on commercial veal farms in Canada, so use of BCS or subcutaneous fat cover assessment may be important variables to capture on arrival as well as weight.

Our ability to assess the effect of supplier was limited by the small percentage of calves supplied to the farm 
by the 10 largest suppliers (each supplying 3 to $10 \%$ of all calves received). Despite the small numbers, we did observe differences among suppliers, but the effects were different in the different models. Access to more detailed data on source-farm calf management would likely be beneficial, although acquiring this information would be very labor-intensive.

A higher standardized price per pound was protective of early mortality. The number of suppliers was large, and therefore the association of price and calf quality may not hold true for all suppliers, but it can generally be said that calf quality was relatively well reflected in price. Following this variable year over year may show how strongly and reliably standardized price reflects mortality risk.

The predictive ability of our models was strongest for early mortality, but was only considered fair. Other on-arrival predictors may not have been captured in our data set that could better identify calves at risk. Further research examining other variables, including body condition on arrival, may help improve veal producers' ability to determine calf quality and provide feedback to the dairy farm of origin. Factors such as dystocia, FPT, and other aspects of early-life management and care are likely to be more directly predictive of mortality risk, but at present, this information at the calf level is not readily available to the Canadian veal industry. Measures that can be easily identified on arrival have more practical application, although the association between early-life care and on-arrival measures is not currently known. The identification of easily obtained surrogate measures for early-life care could have a substantial effect on both the welfare of calves entering the veal industry, as well as on all calves on the dairy farm of origin.

A more complete explanation of on-arrival risk factors for dairy-breed veal calves, including trace-back to the dairy farm of origin and transport, will not only help productivity and the welfare of calves in the veal industry, but also help the dairy industry improve the care of calves of both sexes while they are housed and managed on the farm of origin. Identifying high- and low-risk calves on arrival may also allow for financial penalties or rewards for upstream care, possibly creating incentives for improved early-life care and ultimately improving the welfare and productivity of male calves born on dairy farms.

\section{CONCLUSIONS}

Based on analysis of the available data, season, barn, and entry weight had the strongest associations with survival to $21 \mathrm{~d}$. The effects of barn may reflect vari- ability in management and employee care and the ability of excellent management to overcome risk factors, as well as the inverse. This was especially clear in barn 1 , which had significantly lower early mortality risk than 4 of the other 5 barns, despite having been designated to receive calves with the poorest appearance at arrival compared with barns 2 and 3. The difference in mortality risk among suppliers also suggests that risk factors related to the dairy farm of origin should be more fully explored, because management factors are likely to vary considerably.

\section{ACKNOWLEDGMENTS}

This study was funded by grants from the Dairy Farmers of Ontario (Mississauga, Ontario, Canada), the Ontario Ministry of Agriculture, Food, and Rural Affairs (Guelph, Ontario, Canada), and the Veal Farmers of Ontario (Guelph, Ontario, Canada).

\section{REFERENCES}

Agriculture and Agri-Food Canada. 2015. Veal supply at a glanceCanada. Accessed Apr. 15, 2016. http://www.agr.gc.ca/ eng/?id=1415860000001.

Borderas, F. T., A. M. B. de Passillé, and J. Rushen. 2009. Temperature preferences and feed level of the newborn dairy calf. Appl. Anim. Behav. Sci. 120:56-61.

Canadian Dairy Commission. 2016. The industry: Production. Accessed Apr. 15, 2016. http://www.cdc-ccl.gc.ca/CDC/index-eng. php?id $=3801$.

De Vries, A., M. Overton, J. Fetrow, K. Leslie, S. Eicker, and G. Rogers. 2008. Exploring the impact of sexed semen on the structure of the dairy industry. J. Dairy Sci. 91:847-856.

Godden, S. M., J. P. Fetrow, J. M. Feirtag, L. R. Green, and S. J. Wells. 2005. Economic analysis of feeding pasteurized nonsaleable milk versus conventional milk replacer to dairy calves. J. Am. Vet. Med. Assoc. 226:1547-1554.

Johanson, J. M., and P. J. Berger. 2003. Birth weight as a predictor of calving ease and perinatal mortality in Holstein cattle. J. Dairy Sci. 86:3745-3755.

Kehoe, S. I., B. M. Jayarao, and A. J. Heinrichs. 2007. A survey of bovine colostrum composition and colostrum management practices on Pennsylvania dairy farms. J. Dairy Sci. 90:4108-4116.

LeBlanc, S. J., K. D. Lissemore, D. F. Kelton, T. F. Duffield, and K. E. Leslie. 2006. Major advances in disease prevention in dairy cattle. J. Dairy Sci. 89:1267-1279.

Lombard, J. E., F. B. Garry, S. M. Tomlinson, and L. P. Garber. 2007. Impacts of dystocia on health and survival of dairy calves. J. Dairy Sci. 90:1751-1760.

Moore, D. A., W. M. Sischo, D. M. Festa, J. P. Reynolds, R. Atwill, and C. A. Holmberg. 2002. Influence of arrival weight, season and calf supplier on survival in Holstein beef calves on a calf ranch in California, USA. Prev. Vet. Med. 53:103-115.

Murray, C. F., and K. E. Leslie. 2013. Newborn calf vitality: Risk factors, characteristics, assessment, resulting outcomes and strategies for improvement. Vet. J. 198:322-328.

Pardon, B., K. DeBleecker, M. Hostens, J. Callens, J. Dewulf, and P. Deprez. 2012. Longitudinal study on morbidity and mortality in white veal calves in Belgium. BMC Vet. Res. 8:26-40.

Raboisson, D., F. Delor, E. Cahuzac, C. Gendre, P. Sans, and G. Allaire. 2013. Perinatal, neonatal, and rearing period mortality 
of dairy calves and replacement heifers in France. J. Dairy Sci. 96:2913-2924.

Roland, L., M. Drillich, D. Klein-Jöbstl, and M. Iwersen. 2016. Invited review: Influence of climatic conditions on the development, performance, and health of calves. J. Dairy Sci. 99:2438-2452.

Sargeant, J. M., T. E. Blackwell, S. W. Martin, and R. M. Tremblay. 1994a. Production practices, calf health and mortality on six white veal farms in Ontario. Can. J. Vet. Res. 58:189-195.

Sargeant, J. M., T. E. Blackwell, S. W. Martin, and R. M. Tremblay. 1994b. Production indices, calf health and mortality on seven red veal farms in Ontario. Can. J. Vet. Res. 58:196-201.

Trotz-Williams, L. A., K. E. Leslie, and A. S. Peregrine. 2008. Passive immunity in Ontario dairy calves and investigation of its association with calf management practices. J. Dairy Sci. 91:3840-3849.

Tyler, J. W., D. D. Hancock, S. E. Wiksie, S. L. Holler, J. M. Gay, and C. C. Gay. 1998. Use of total protein as a predictor of calf mortality. J. Vet. Intern. Med. 12:79-83.
Vasseur, E., J. Rushen, and A. M. de Passillé. 2009. Does a calf's motivation to ingest colostrum depend on time since birth, calf vigor, or provision of heat? J. Dairy Sci. 92:3915-3921.

Wells, S., D. A. Dargatz, and S. L. Ott. 1996. Factors associated with mortality to 21 days of life. Prev. Vet. Med. 29:9-19.

Wilson, L. L., J. L. Smith, D. L. Smith, D. R. Wolfgang, and E. F. Wheeler. 2000. Characteristics of veal calves upon arrival, at 28 and 84 days, and at end of the production cycle. J. Dairy Sci. 83:843-854

Windeyer, M. C., K. E. Leslie, S. M. Godden, D. C. Hodgins, K. D. Lissemore, and S. J. LeBlanc. 2014. Factors associated with morbidity, mortality, and growth of dairy heifer calves up to 3 months of age. Prev. Vet. Med. 113:231-240. 